\title{
Characterization of holding brake friction pad surface after pin-on-plate wear test
}

\author{
Drago, N.; Gonzalez Madruga, D.; De Chiffre, L.
}

Published in:

Surface Topography: Metrology and Properties

Link to article, DOI:

10.1088/2051-672X/aaabd3

Publication date:

2018

Document Version

Peer reviewed version

Link back to DTU Orbit

Citation (APA):

Drago, N., Gonzalez Madruga, D., \& De Chiffre, L. (2018). Characterization of holding brake friction pad surface after pin-on-plate wear test. Surface Topography: Metrology and Properties, 6(1), [015007].

https://doi.org/10.1088/2051-672X/aaabd3

\section{General rights}

Copyright and moral rights for the publications made accessible in the public portal are retained by the authors and/or other copyright owners and it is a condition of accessing publications that users recognise and abide by the legal requirements associated with these rights.

- Users may download and print one copy of any publication from the public portal for the purpose of private study or research.

- You may not further distribute the material or use it for any profit-making activity or commercial gain

- You may freely distribute the URL identifying the publication in the public portal

If you believe that this document breaches copyright please contact us providing details, and we will remove access to the work immediately and investigate your claim. 
Characterization of holding brake friction pad surface after pin-on-plate wear test

N Drago ${ }^{1}$, D Gonzalez Madruga ${ }^{2}$, L De Chiffre ${ }^{1}$,

${ }^{1}$ Department of Mechanical Engineering, Technical University of Denmark, Produktionstorvet, Building 425, DK- 2800, Kgs. Lyngby, Denmark.

${ }^{2}$ Current address: MAN Diesel \& Turbo, Teglholmsgade 41, DK-2450 Copenhagen SV, Denmark

nicola.drago@psdservices.eu, daniel.madruga@man.eu, ldch@mek.dtu.dk

Corresponding author: dagoma@mek.dtu.dk

Keywords: holding brake friction pad, wear, surface characterization, plateau, segmentation

\begin{abstract}
The article concerns the metrological characterization of the surface on a holding brake friction material pin after a pin-on-plate (POP) wear test. The POP test induces the formation of surface plateaus that affect brake performances such as wear, friction, noise and heat. Three different materials' surfaces have been characterized after wear from data obtained with a focus variation 3D microscope. A new surface characterization approach with plateau identification is proposed, using the number of plateau on the surface, equivalent diameter, length and breadth, as measurands. The identification method is based on determining and imposing ISO 27158-2 Lower Plateau Limit (LPL) in Material Probability Curves and on applying a combined criterion of height segmentation threshold and equivalent diameter threshold. The method determines the criterion thresholds for each material since LPL appears typical by material. The method has allowed quantifying the surface topography at two different levels of wear. An expanded measurement uncertainty of $3.5 \mu \mathrm{m}$ for plateau dimensions in the range $50-2000 \mu \mathrm{m}$ and one of $0.15 \mu \mathrm{m}$ for plateau heights up to $10 \mu \mathrm{m}$ have been documented.
\end{abstract}

Keywords: holding brake friction pad, wear, surface characterization, plateau, segmentation

\title{
1 Introduction
}

In the last years, there has been a growing attention to surface morphology of brake materials and its influence on brake performance. Experience from the automotive shows that friction coefficient, wear and squeal correlate with surface number of plateau on the surface and size [1,2] and that different wear mechanisms intervene depending on pressure applied in braking and temperature [2]. The importance of plateaus contrasts with the scarce literature being available for non-automotive applications, such as that for holding brakes. State of the art is represented by automotive literature, which utilized stereo-microscope micrograph imaging and Otsu's algorithm to segment surface and distinguish plateaus by monochromatic contrast [1]. ISO 25178-2 [3] recommends Material Probability Curve (MPC) approaches for plateau detection on lapped, ground or honed surfaces and a "toolbox" of pattern recognition techniques based on Maxwellian surface over-segmentation Wolf-pruning or on fractal methods. Research has been carried out on articraft surface segmentation [4], on bio-inspired functional texturing [5]. Literature is reported [6] that interprets brake friction behaviour, including hysteresis, based on cellular automata, artificial intelligence or state observer approaches applied to brake surface topography. Still, there is room for more information on dynamically segmenting surfaces that are not designed to maintain a deterministic texture -at least to date-, such as those of holding brakes. Scope of this article is to discuss a traceable application of the MPC approach to identify and measure plateaus on natural segmented brake-pad surfaces with use of focus variation 3D microscopy, software-based height segmentation, and image post-processing.

Subject of this investigation are sliding surfaces of six pins made of yaw-drive unit holding brake materials for wind energy system. Three different materials and two specimens per material are assessed. Material "a" is a fibre composite made with glass fibre yarn and woven coarse textile bonded with thermoset, later also called "woven fibre composite". Material "b" is a polyamide PA66 with short glass and aramid fibres later also called "polyamide". Material "c" is a composite with non-woven fibres and high porosity later also called "nonwoven fibre composite". All specimens underwent same Pin-On-Plate (POP) test conditions apart lubrication (material "a" and "b" were not lubricated). The POP test is particularly suitable for wear investigations characterised by low speed and motion inversions [7]. Sliding on plate runs-in, changes and wears the pin surface with generation and modification of plateaus by different mechanisms [8,9]. Pins of same material 
showed to have different levels of wear. In this article, for each material, two wear levels are assessed ("a-1", "a-2", "b-1", "b-2", "c-1", "c-2", where index "1" indicates less wear in terms of height reduction compared to the initial pin height while "2" indicates a more worn pin).

\section{Characterization methodology}

The plateau detection and measurement methodology proposed in this article is an application of MPC approach ISO 25178-2 and ISO 13565-3 $[3,10]$ to a natural surface which is relatively simpler than watershading and Wolf-pruning. The methodology needs to detect significant features (plateaus) and exclude nonrelevant features such as spikes, debris, dales and scratches. To do this, the methodology relies on height segmentation on the Z-axis and equivalent diameter thresholding on the $\mathrm{X}-\mathrm{Y}$ plane and on a series of parameters related to plateaus: upper plateau limit (UPL), lower plateau limit (LPL), lower valley limit (LVL). ISO 25178-2 [2] shows a scale-limited surface with its corresponding areal MPC and the regions used in the definitions of parameters UPL, LPL, UVL, and LVL. Rpq, Rvq and Rmq. They are respectively slopes of linear regressions through the plateau and the dale region, and plateau-to-dale areal material ratio at the plateau-to-dale intersection. A flowchart of the methodology is shown in Figure 1.



Figure 1: flowchart with characterization routine utilized in this article

In more details, the methodology consists of eight steps:

1. taking 2D surface texture images. Focus variation (Alicona Infinite Focus) texture images at 20x magnification were taken in the rectangle areas $\alpha, \beta$, $\gamma$ and/or $\delta$ of Figure 2 as per Table 1 with three aims: carrying out the analysis, enabling robustness analysis in at least two cases (a-2 and b-1), and minimizing measurement time. Rectangles $\alpha$ and $\beta$ were $4.185 \mathrm{~mm}$ * $3.230 \mathrm{~mm}$ size and rectangles $y$ and $\delta$ were $3.854 \mathrm{~mm} * 2.825 \mathrm{~mm}$ size. This difference in dimension allowed a symmetric coverage of specimen surface and inclusion of central parts and more external parts in same measurement $(\alpha, \beta)$. The latter characteristic was aimed at a future analysis involving profile and 
form measurements [11]. LPL was calculated analytically. The measurements were taken in a controlled laboratory conditions at DTU. Image post processing (SPIP 6.6.5, Image Metrology) was used to process the images taken in the measurement and characterize the sample surface.

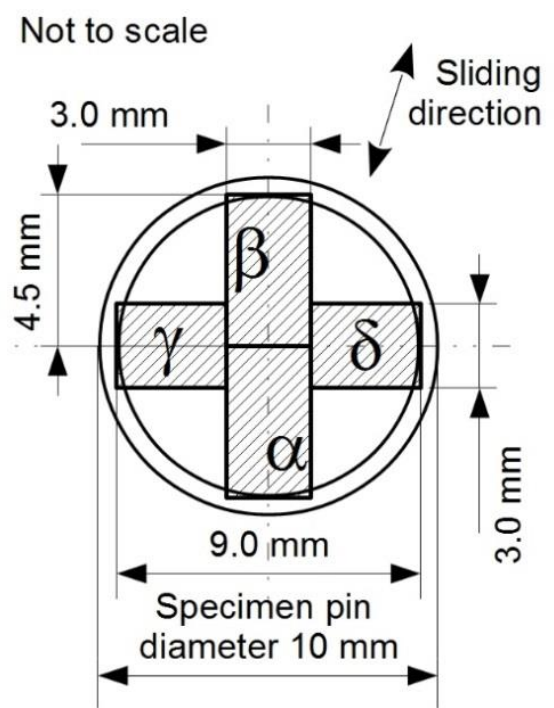

Figure 2: measurement strategy

Table 1 : measurement areas

\begin{tabular}{|c|c|c|c|c|}
\hline \multirow{2}{*}{ Specimen } & \multicolumn{4}{|c|}{ Rectangle area } \\
\hline & $\alpha$ & $\beta$ & $\mathrm{y}$ & $\delta$ \\
\hline $\mathrm{a}-1$ & $\mathrm{x}$ & & & \\
\hline $\mathrm{a}-2$ & $\mathrm{x}$ & $\mathrm{x}$ & $\mathrm{x}$ & $\mathrm{x}$ \\
\hline $\mathrm{b}-1$ & $\mathrm{x}$ & $\mathrm{x}$ & $\mathrm{x}$ & $\mathrm{x}$ \\
\hline $\mathrm{b}-2$ & $\mathrm{x}$ & & & \\
\hline $\mathrm{c}-1$ & & $\mathrm{x}$ & & \\
\hline $\mathrm{c}-2$ & $\mathrm{x}$ & & & \\
\hline
\end{tabular}

2. Taking 3D surface height measurement. Each specimen underwent height measurement along the z-axis according to the above-mentioned parameters. Both 2D images and 3D measurements were analysed after a global levelling and a bow levelling. No further filtering, in noise or wavelength, and no resolution changes were applied. Image processing software rendered MPC as detailed as 500 points.

3. Calculating core parameters UPL and LVL. In MPCs, $S_{p k}$ is the height of the area of the triangle of material protruding out of the core surface having $S_{\mathrm{mr} 1}$ as base, which means that $S_{\mathrm{pk}}$ is higher than core materials but lower than spikes. On the same note, $S_{\mathrm{vk}}$ corresponds to the height of the dale area triangle with base $100 \%-S_{\mathrm{mr} 2}$ i.e. S $\mathrm{vk}$ is the average height of the protruding dales below the core surface. From observation on overlapped texture images, height segmentations and roughness maps (not reported in this article), segmenting at $S_{\text {mr1 }}+S_{\text {pk }}$ proved cutting out spikes and top fibres of a few primary plateaus while segmenting at $S_{m r 2}+S_{v k}$ only cut out scratches in the bottom of valleys. No commercial software calculated UPL and LVL at the time of the article, whereas they calculated parameters $S_{\mathrm{mr} 1} ; \mathrm{S}_{\mathrm{pk}} ; \mathrm{S}_{\mathrm{mr} 2}$ and $\mathrm{S}_{\mathrm{vk}}$. Therefore, the methodology is based on the assumption that $U P L=S_{m r 1}+S_{p k}$ and $L V L=S_{m r 2}+S_{v k}$. UPL and $L V L$ are utilized in the calculation of $L P L$.

4. Calculating core parameter LPL. LPL was calculated analytically according to [2] implementing the second conic section fit procedure.

5. Detecting plateaus through simultaneous imposition of two thresholds: LPL on the z-axis and a minimum equivalent diameter on the $x-y$ axis of $50 \mu \mathrm{m}$ (Equation 1). An equivalent diameter 
threshold of $50 \mu \mathrm{m}$ was imposed according to automotive literature [6] to neglect potential debris. Below such threshold, detected feature number increases greatly while covered area remains almost constant.

$$
\text { Equivalent diameter }=\text { Eq. diam. }=\emptyset_{\text {eq }}=\sqrt{\frac{4 *(\text { enclosed area })}{\pi}}
$$

Equation 1: equivalent diameter

6. Verifying meaningfulness of detected features by visual comparison with texture image [12] and selected 2D profiles helps verifying qualitatively software detections and learn on surface features such as potential fibres or boundaries between primary and secondary plateaus;

7. Plateau measurement according to relevant measurands: number, equivalent diameter, $Z$ mean, breadth and length (Figure 3). The choice of measurands is a relevance trade-off between function and metrological analysis. The number of detected plateaus (No.) correlates positively with friction coefficient [1]. It is determined by image post-processing software count of features detected after imposing the criterion including on partial plateaus on image borders. The plateau covered area is a percentage that measures the ratio between the bearing area as determined by the LPL

segmentation plane and the total surface horizontal area. It correlates positively with wear [1]. Mean plateau equivalent diameter (eq.1) allows the plateaus size quantification. Mean breadth of plateaus is the average of plateaus' longest cord perpendicular to the angle $\theta$ (Figure 5 right). If the feature was rotated so that the moment's axis becomes parallel to the x-axis, then breadth is the extension of a bounding rectangle in the vertical direction. Mean width of plateaus is the average of plateaus' longest cord along the angle $\theta$ given by the moment's axis to the $x$-axis.
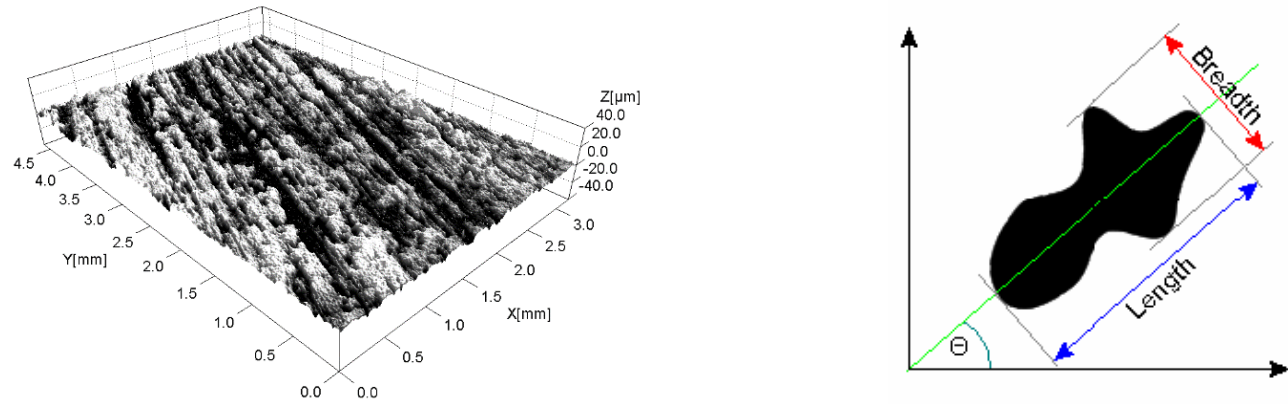

Figure 3: (Left) Example of a pad surface, (right) plateau length and breadth definition (Image Metrology)

8. Sensitivity analysis. Sensitivity analysis is inspired by [4] and assesses measurand behaviour between the extremes at which method validity decayed, and in the surroundings of LPL. Only one parameter, height, is varied because it is the most significant parameter of this analysis. Moreover, changing multiple parameters that influence plateau detection would easily increase the number of possible combinations [4]. Sensitivity analysis was carried out at different height points. Such points were named as in Figure 4, from top to bottom: highest point beyond which feature detection capacity decayed (i.e. last equivalent diameter became smaller than $50 \mu \mathrm{m}$ ) was named point 1 ; height-distance between UPL and LPL was pitched and numbered from 2 to 8 ; one same-distance (point 9) was added on bottom of LPL below which other characteristics decayed (number, length). Measurands were gauged at each one of nine height points. 




Figure 4: sensitivity analysis, segmentation height points

\section{Surface topography characterization of specimens}

This section describes findings of the chosen methodology in specimen surface characterization.

Texture images. The texture images of Figure 5 display material differences. For specimens a- 1 and a-2, it is possible distinguishing large sliding areas of binder material and emerged or embedded flakes of harder material (the darker spots with elliptic-like profile). Both are bearings or plateau areas. Teared-off flakes expose lower layers, material fibres and create discrete craters. When detached and dragged, such fibres create long grooves. Specimens b-1 and b-2 in thermoplastic resins have a more repeatable distribution of features, oriented along the sliding direction. In such specimens, it is possible distinguishing primary plateaus, which are the lighter-colour fibres slightly protruding from secondary plateaus (white colour) as per figure 6 .

Secondary plateaus are the larger light-brownish areas formed by compacting debris. Grey areas are interconnected valleys through which debris and flakes flow. Darkest areas are scratches or pits due to teared-off fibres. Specimens c-1 and c-2, less intelligible by texture, are made of a porous material with large plateau areas rich in hard nested fibres flattened by sliding. Specimens c-1 and c-2 do not show the orientation of sliding, probably due to the nesting of such fibres, which limits material relocation. Debris and flakes tend to fill in pores and pits. The dark colour reduces effectiveness of increasing image contrast as a visual help. 




a-1

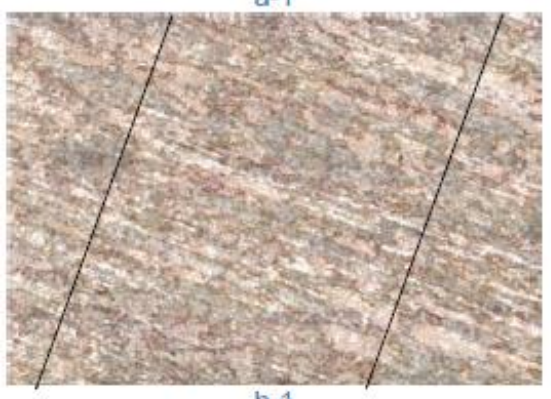

b-1

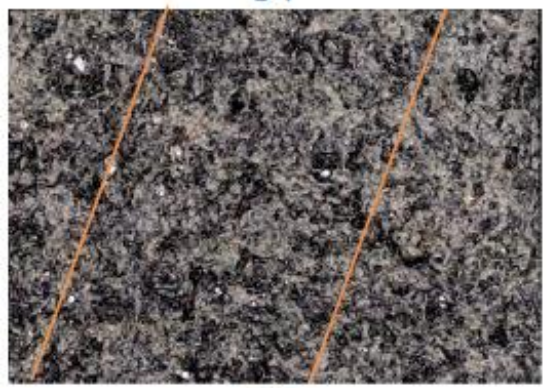

C-'

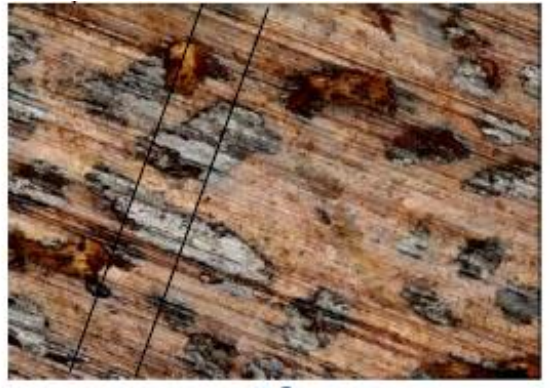

a-2



b-2

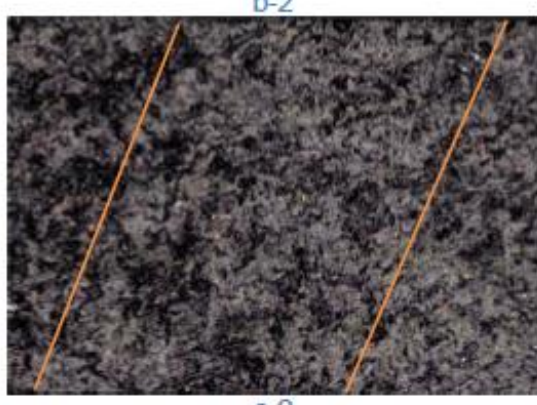

$\mathrm{c}-2$

Figure 5: Surface textures. Image dimensions are $4.64 \mathrm{~mm}$ * $3.23 \mathrm{~mm}$. Pin materials: a) woven fibre composite; b) polyamide 66; c) non-woven fibre composite. Least worn specimens (index "1") are the on the left, most worn ("2") on the right. Lines indicate position of profiles displayed in Figure 7.

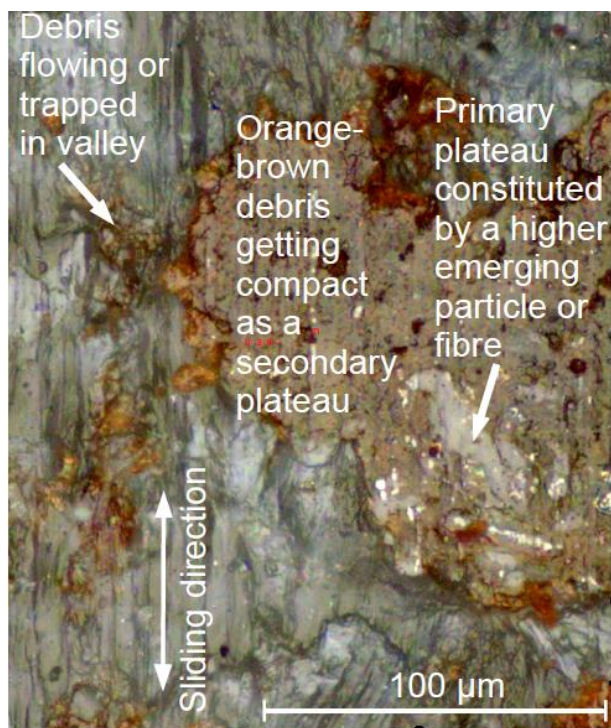

Figure 6: surface features detection for material b-2

Because each material presents different features, two profiles per specimen are taken to include relevant features and to provide a first assessment of the surface. The zero height is determined as the mean height 
Zmean on complete 2D height images. Plateaus are those features that emerge beyond LPL threshold. Specimens a-1 and a-2 have craters, emerging fibres and relatively smooth and large bearing parts surrounding such features. Though without craters or high fibres, specimen $b-1$ and $b-2$ are generally rougher than specimen a-1 and a-2. Specimen b-1 and b-2 present shorter and relatively more numerous emerging features than the first two specimens. The c-1 and c-2 specimens are evidently coarser and include pores also in the plateau areas. Profile representativeness of the surface may be questionable, especially when single events such as protruding fibres or craters are wide compared to the complete image (e.g. specimen b-1 crater length is $40 \%$ of image width), or not repeated. Moreover, plateaus can be at different heights and profiles appear closer to roughness profiles than to industrial plateaued surfaces (Figure 7).
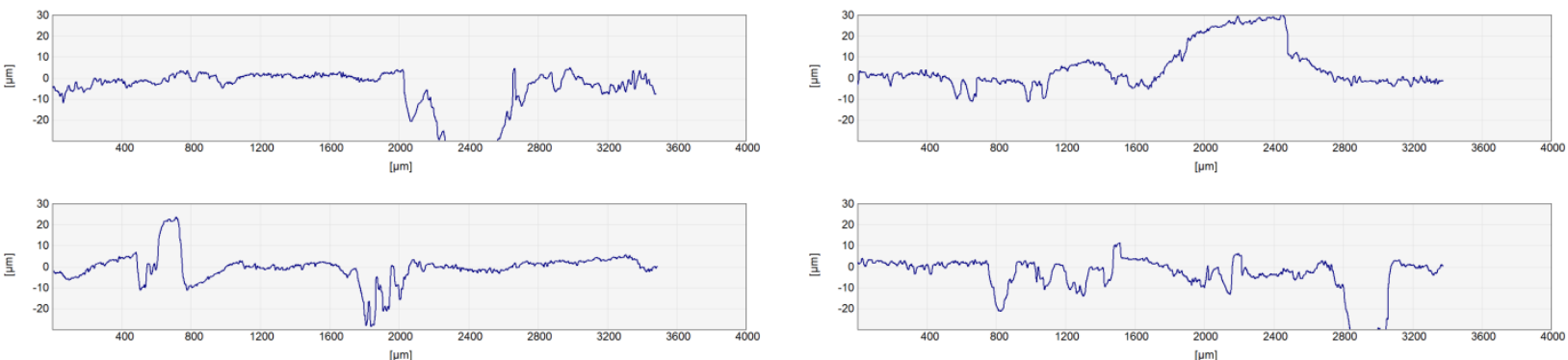

a-1


b-1
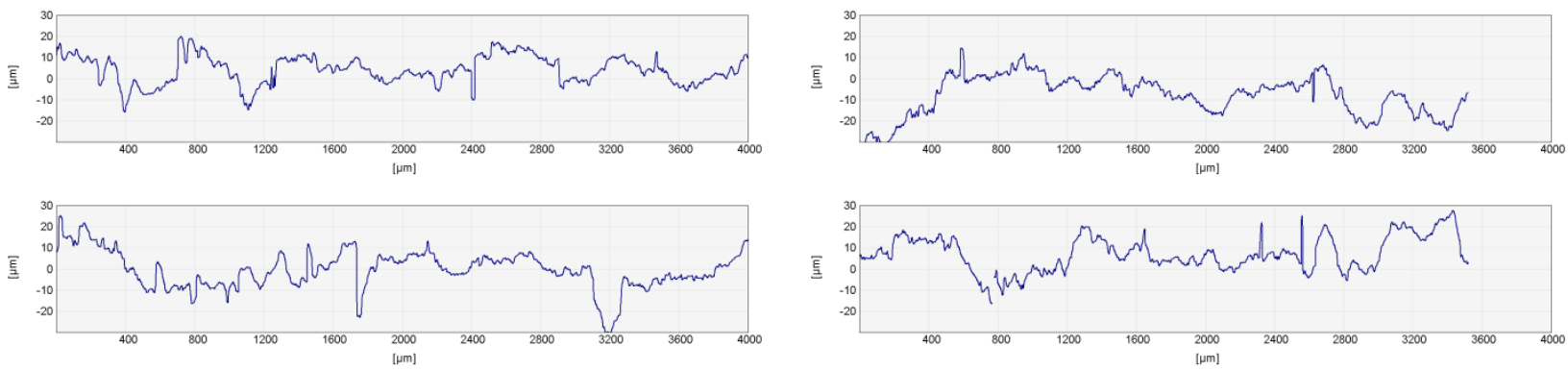

C-1

c-2

Figure 7: levelled profiles perpendicular to the sliding direction (profile positions on surfaces are shown in Figure 5). Least worn specimens in the left column, most worn ones in the right column.

MPC normalization and LPL calculation. LPL is considered the point at which the plateau tract of material probability curve ends before the transition to the valley tract. Section 4.4.5.2 of ISO 25178-2 [3] shows the MPC of a honed surface, quite an ideal curve compared to specimen curves (Figure 8) related to stochastic surfaces with less clear plateau tracts and valley tracts. There may appear different cases: two distributions, more than two (like in b-1) or just one distribution as for specimen c-2. In such c-2 specimen only one area out of four, with sole global levelling instead of global levelling and bow removal as per all other images, showed the sought two distributions. On c-2, applying different levelling induced morphological variations as large as $92 \%$ increase (from 13 to 25 ) in detected feature number and $8 \%$ decrease (52\% to $49 \%$ ) in covered area after bow removal. Here onwards, in c-2 LPL height is defined after the sole global levelling but detection is carried out after both global levelling and bow removal. Visual verification of features on texture helps understanding physical boundaries in all cases. The proposed method is therefore capable to 
determine LPL analytically in five out of six surfaces and is limited to materials that show different distributions in the plateau and the valley area. By comparing the profiles of Figure 7 with the normalized material probability curves portrayed in Figure 8 , it is possible seeing that LPL are all in the surrounding of $\mathrm{z}=0$, which is the mean height. It is also possible noticing that the coarser the profiles (specimens $b-1$ and $b$ 2 being the smoothest, specimen c-1 and c-2 being the coarsest), the flatter is the normalized MPC. Research could be carried out on different methods $[13,15]$ to assess plateau detection effectiveness in materials like c-1 and c-2 whose colour and morphology make MPC or texture analysis more difficult.

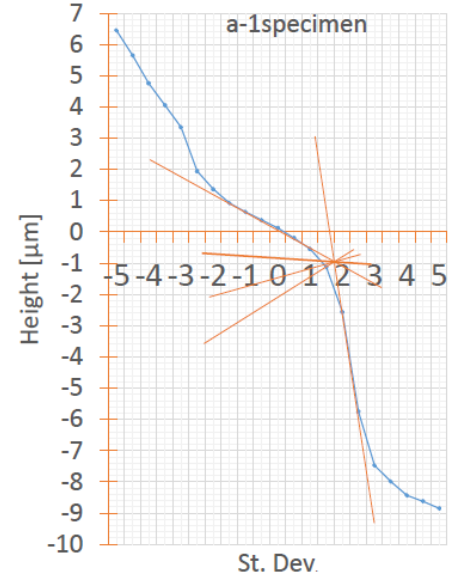

$\mathrm{a}-1 \mathrm{LPL}=-0.710 \mu \mathrm{m}$

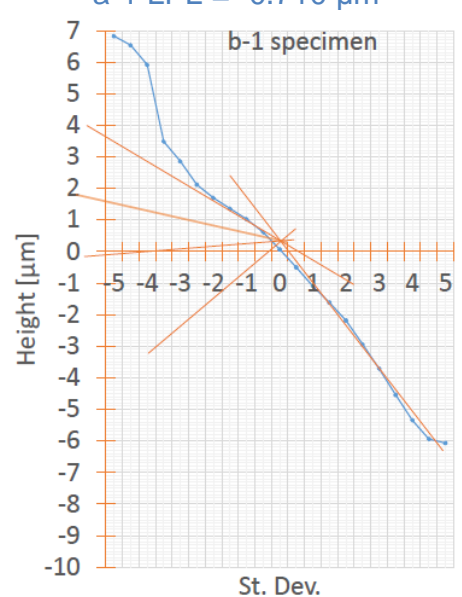

b-1 LPL $=-0.168 \mu \mathrm{m}$

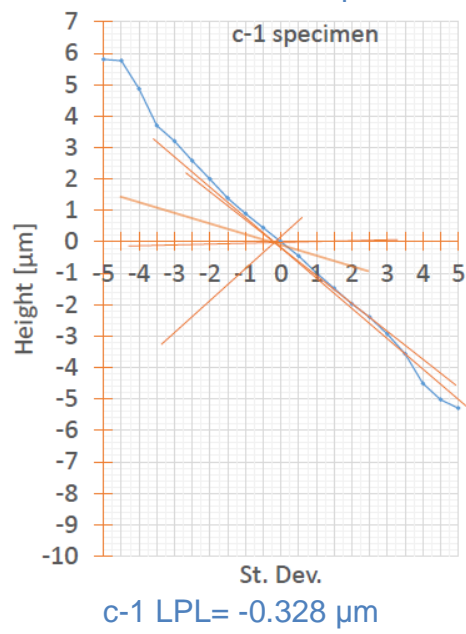

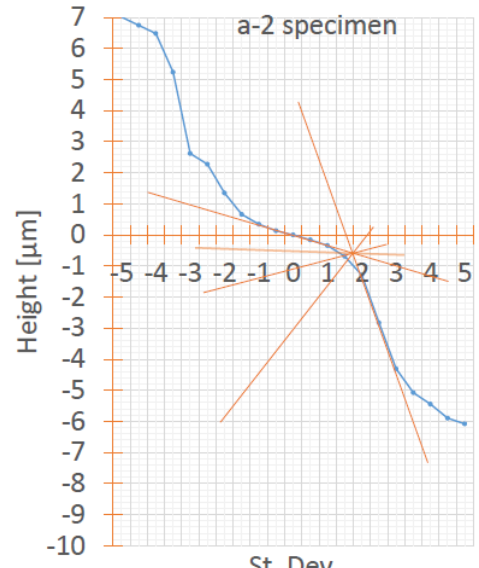

St. Dev. a-2 LPL $=-0.567 \mu \mathrm{m}$

b-2 specimen

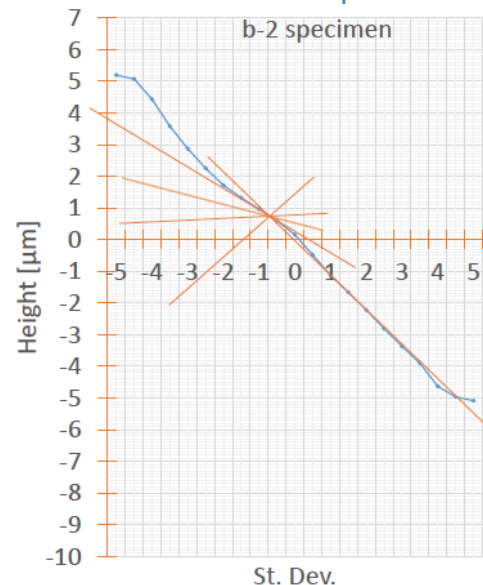

b-2 LPL $=0.475 \mu \mathrm{m}$



Figure 8: LPL determination through normalized MPC (ISO 25178-2, for graphical details ISO 13565-3:1998 annex $A)$. LPL is the intercept between the thickest orange secant and the blue curve. Least worn specimens 
in the left column, most worn ones in the right column. $a-1 L P L=-0.710 \mu m, a-2 L P L=-0.567 \mu m, b-1 L P L=$ $-0.168 \mu \mathrm{m}, b-2 L P L=0.475 \mu \mathrm{m}, c-1 L P L=-0.328 \mu \mathrm{m}, c-2 L P L=0.243 \mu \mathrm{m}$.

Plateau detection through LPL height segmentation and imposition of minimum $\varnothing_{\text {eq. }}$. Results of surface segmentation by imposition of LPL threshold and the equivalent diameter threshold are shown in Figure 9. Each coloured spot is a separate plateau higher than LPL and larger than the equivalent diameter as detected by the image processing software. The segmentation enables a visual perception of feature shape, orientation, border indentation and number of plateaus in the three materials and two specimens of same material. It is possible distinguishing that same material shares similar large shapes while different materials have different large shapes. While plateaus of material "a" (a-1, a-2) and "b" (b-1, b-2) show a marked orientation along the sliding direction, material "c" (c-1, c-2) does not. 

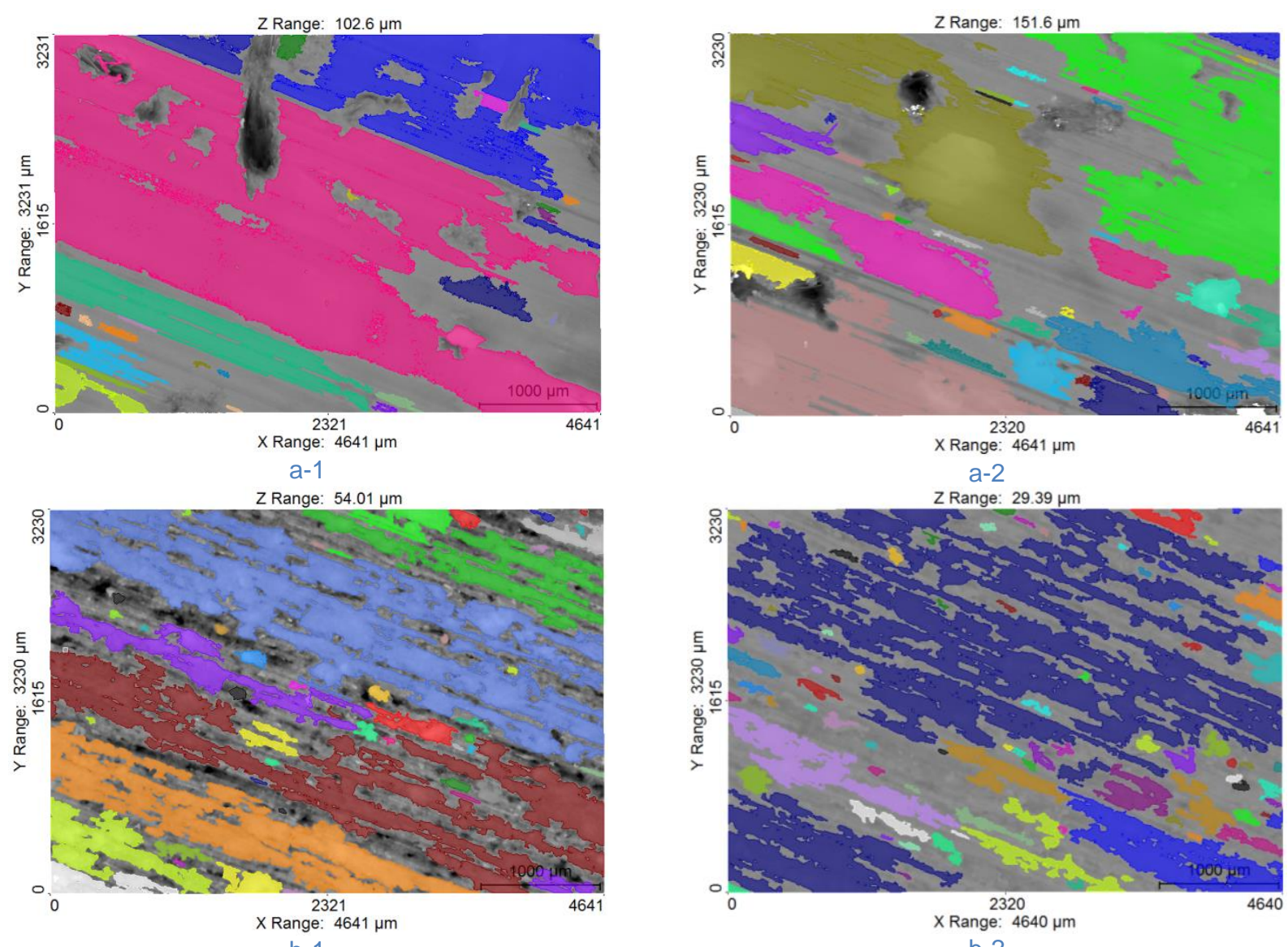

b-1
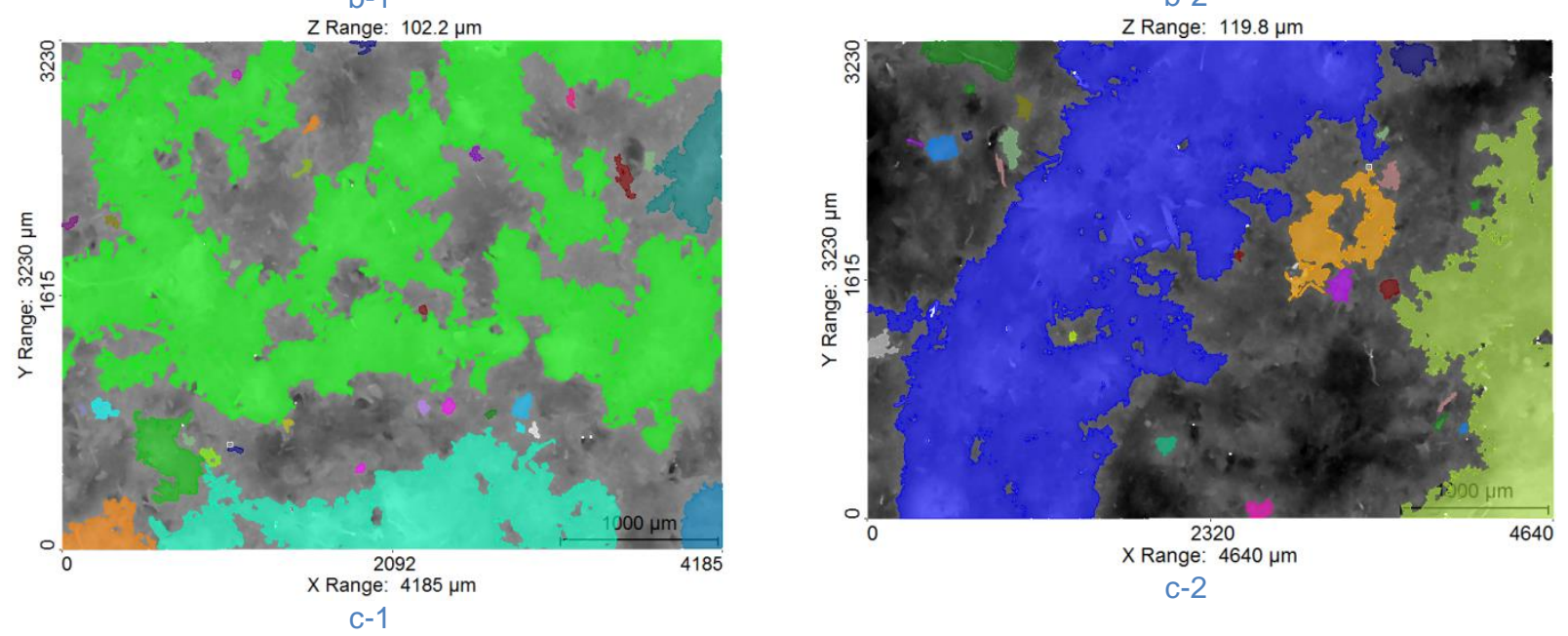

Figure 9: Plateau detection in colour according to LPL height thresholding (ref. Figure 8) and imposition of $\varnothing_{\mathrm{eq}} \geq 50 \mu \mathrm{m}$. In each image, each separate plateau is shown in a different colour. Grey-scaled background is the height map of the surface (the darker the grey, the deeper the valley or scratch). Least worn specimens in the left column, most worn ones in the right column.

Plateau dimension and height. Plotting plateau mean height vs. equivalent diameter shows that plateaus are distributed over a height range and that their scatter is similar by material. Excluding outliers -smallest and highest features- it appears that the least worn specimens -left column of figure 10 i.e. specimens a-1, b-1, c-1- have more mid-sized (roughly $400 \mu \mathrm{m}$ to $1600 \mu \mathrm{m}$ ) plateaus. In materials "a" and "b" such plateaus are in the surroundings of $2 \mu \mathrm{m}$ height whereas in material "c" they are especially between $6 \mu \mathrm{m}$ and $8 \mu \mathrm{m}$ height. 


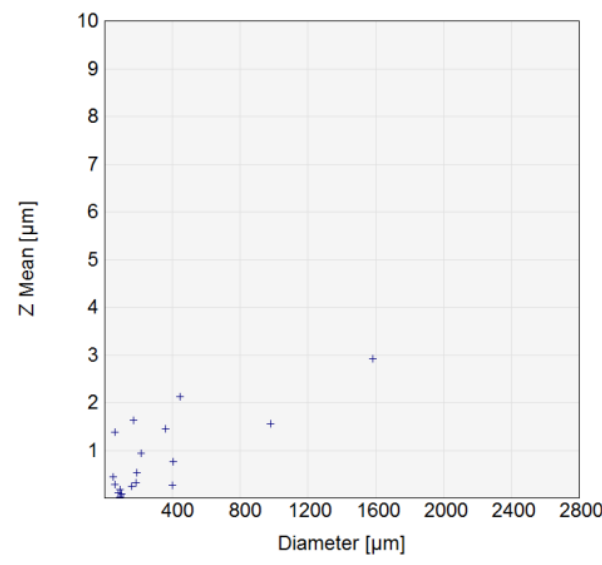

a-1

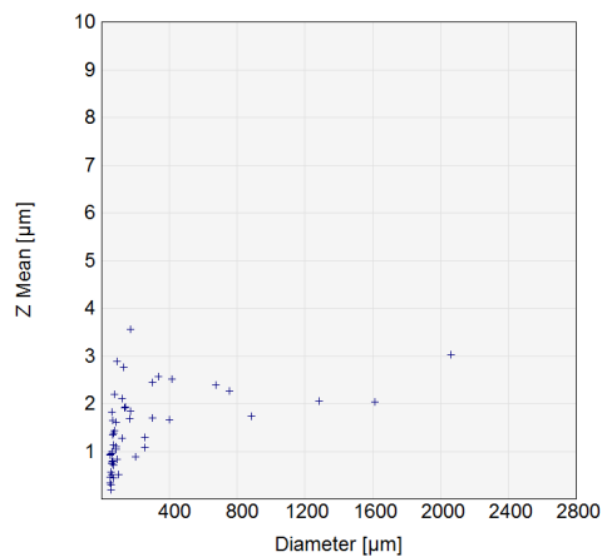

b-1

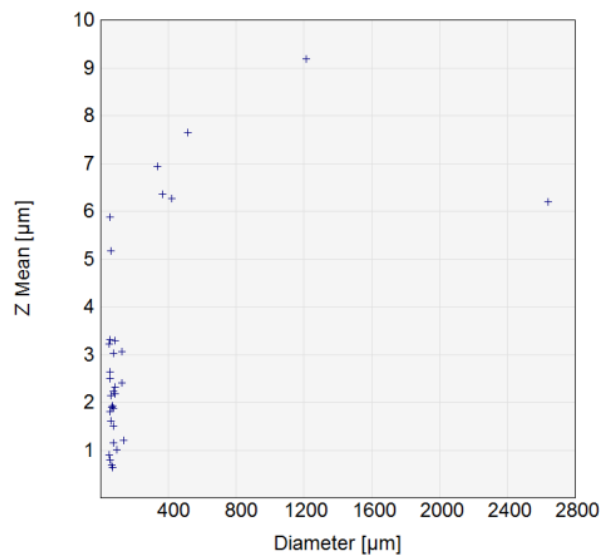

C-1

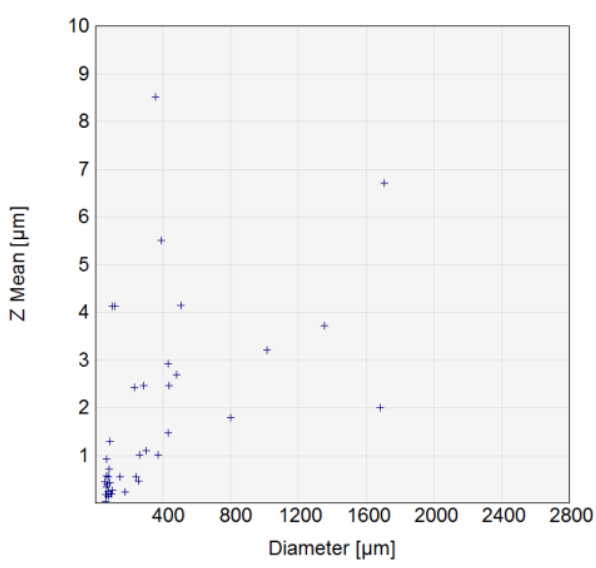

a-2

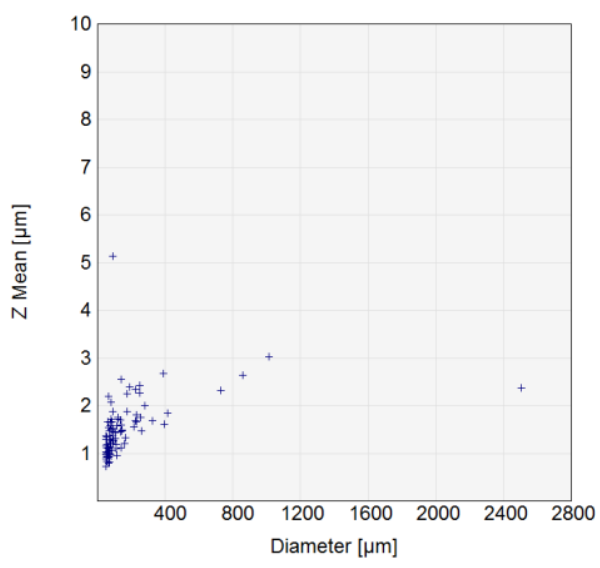

b-2



c-2

Figure 10: plots of plateau mean diameter by plateau mean height position at LPL segmentation height. Least worn specimens in the left column, most worn ones in the right column.

Measurand sensitivity to height threshold variation was tested according to Figure 4 at variations pitched between method validity degeneration points 1 and 9 . Upper left Figure 11 is interpreted to confirm that least-worn specimens of any material (a-1, b-1, c-1) have more plateaus per unit of surface at mid heights, especially between segmentation threshold 4 and segmentation threshold 6 . On the contrary, such specimens have less plateaus down close to plateau-roots level i.e. segmentation levels 7 and 8 . In upper right Figure 11, it is possible to see that least-worn specimens have systematically a larger plateau-covered area than their most-worn homologue throughout any height threshold down to LPL roots. Figure 11 bottom 
left (plateau mean equivalent diameter) and right (mean equivalent length) appears showing that least-worn $\mathrm{a}-1$ and $\mathrm{b}-1$, though not c-1, have larger equivalent-diameter plateaus. These could be seen as larger-base plateaus compared to those of more worn $a-2$ and b-2. Plateau mean breadth diagram substantially replicates plateau mean equivalent diameter behaviour and would be redundant.
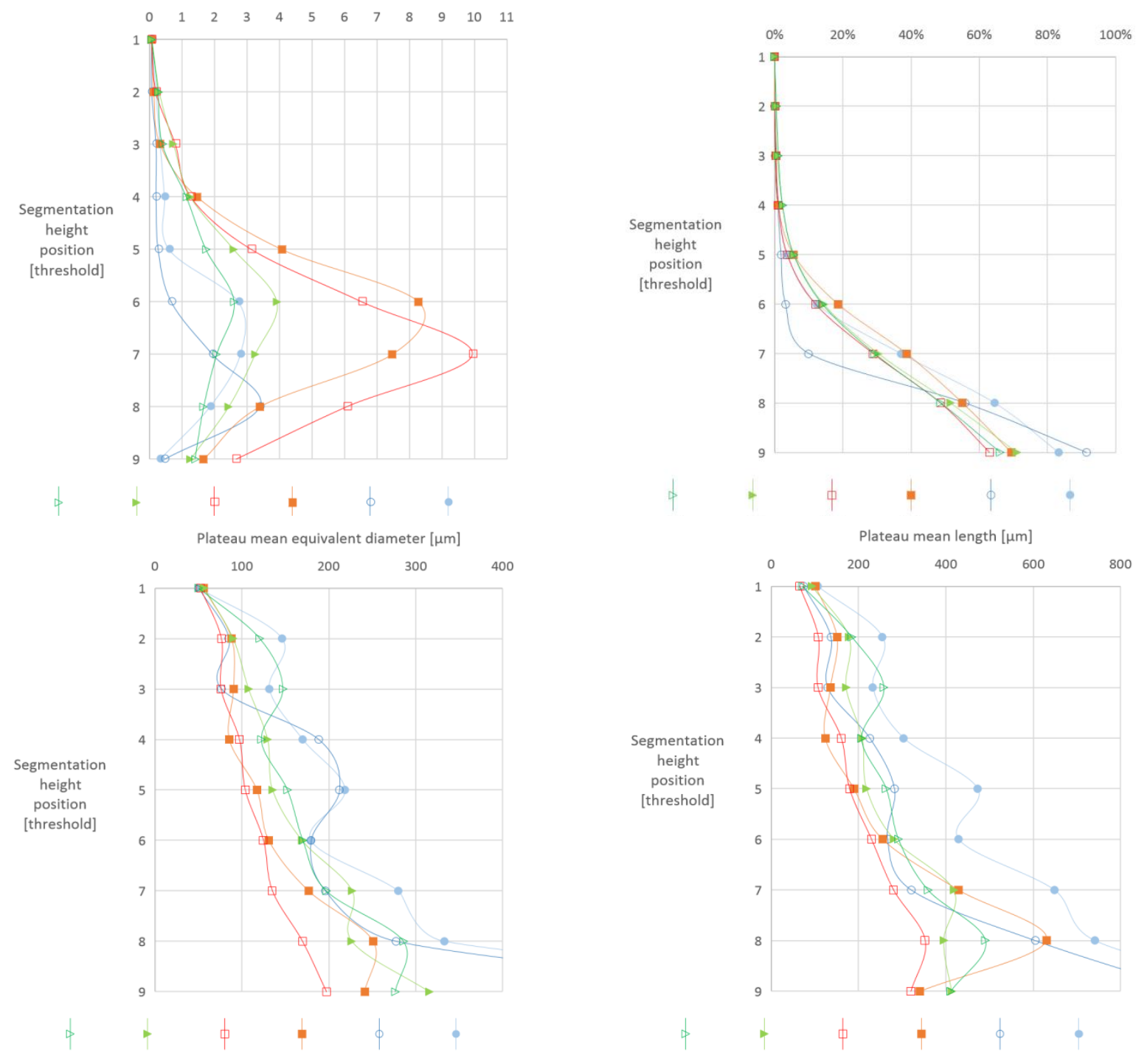

Figure 11: height segmentation sensitivity analysis, from ceiling point (point 1, ref. Figure 4) to bottom point (point 9, ref. Figure 4) of method applicability. Least worn specimens are those with "1" index, most worn ones are those with "2" index.

Robustness analysis. The software is extremely repeatable, in the sense that it repeated same identical results under same procedure and conditions in calculating plateau count and covered area. Because of this, the robustness analysis focuses on the applicability of the MPC method on specimen stochastic surface. The robustness assessment (results in Figure 12) takes into account the dispersion of LPL coordinates as determined by the angle secant methodology proposed in this article. The robustness sums up method, software detection and operator decisions in curve normalization. Robustness assessment is based on replicating the method on four measured areas $(\alpha, \beta, \gamma, \delta)$ of specimen $a-2$ and $b-1$ as per Figure 2 . Because of the limitations explained in the MPC paragraph and in figure 4 it was not possible reporting on material "c". 
LPL height range was $0.30 \mu \mathrm{m}$ for material "a" and $0.32 \mu \mathrm{m}$ for material "b" though with an outlier extending the range to $0.762 \mu \mathrm{m}$, one order of magnitude smaller than plateau height.

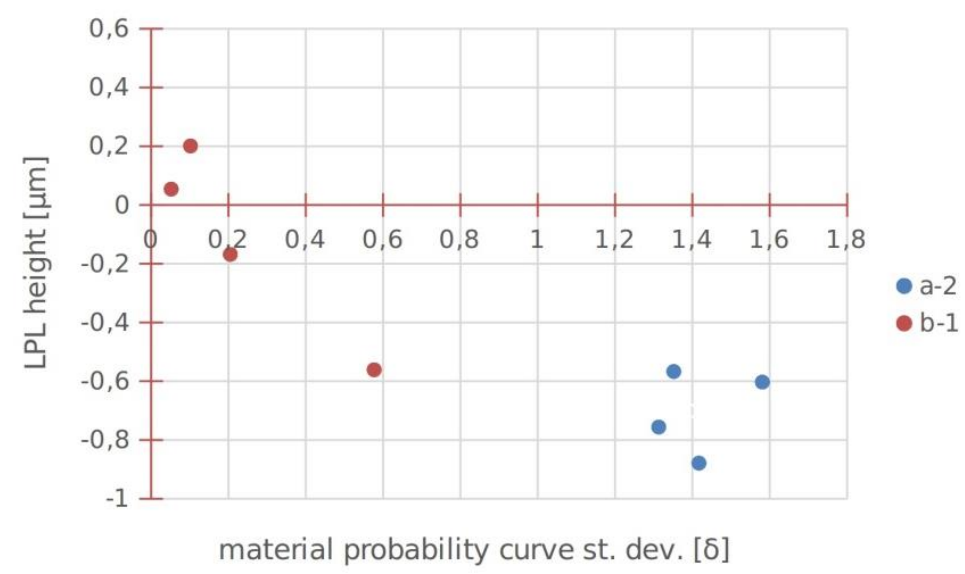

Figure 12: LPL position in four areas of specimen "a-2" and specimen "b-1".

\section{$4 \quad$ Uncertainty estimation}

Calibration for $X / Y$ was carried out using an Alicona calibration standard (see Figure 13) while the Z-axis was calibrated using a step-height artefact developed by DTU (Figure 14). The calibration and test uncertainty for the $X / Y$ and $Z$ axis have been calculated using equation 2 and considering conclusions of [14].

$$
U=2 \cdot \sqrt{u_{r}^{2}+u_{p}^{2}+u_{m}^{2}} \text { eq.2 }
$$

In the case of $X / Y$ calibration, $u_{r}$ is the standard uncertainty of the calibration standard, $u_{p}$ is the standard deviation of 25 repetitions on the relevant circle diameter in the calibrated standard, and $u_{m}$ is the uncertainty from the resolution of the measurement. In the case of the sample measurements, $u_{r}$ is the standard uncertainty of the calibration, $u_{p}$ is the uncertainty from the sample measurement repeatability calculated as the standard deviation of a plateau equivalent diameter 5 repetitions, and $u_{m}$ is the uncertainty from the resolution of the sample measurement. The Alicona calibration standard contains three featured circles with different diameters (Table 2). The selected circle sizes correspond approximately to key plateau sizes, namely to: plateau threshold equivalent diameter, plateau mean equivalent diameter, and plateau maximum equivalent diameter of larger plateaus. The calibration was performed at a temperature of $20 \pm 1^{\circ} \mathrm{C}$.

Table 2: calibration uncertainty

\begin{tabular}{|c|c|}
\hline Nominal circle diameter $/ \mu \mathrm{m}$ & Expanded uncertainty, Ur $(\mathrm{k}=2) / \mu \mathrm{m}$ \\
\hline 50 & 1 \\
\hline 250 & 1 \\
\hline 2000 & 2 \\
\hline
\end{tabular}

Image processing software measures 2D images in pixels. Pixels are then converted into metric units by scaling. The circle is determined as the series of low points according to Figure 13 right. When $x$-axis was magnified, circle edges showed a grey-value slope effect. Scaling diameter was taken on the central part of the grey-value slope giving a scaling ratio of $0.439 \mu \mathrm{m}$ per pixel. Standard deviation for the reference circles was $0.011 \mu \mathrm{m}$ for the 50 and $250 \mu \mathrm{m}$ and $0.212 \mu \mathrm{m}$ for the $2000 \mu \mathrm{m}$ circle (Table 3 ). The calibration uncertainty budget shows that the largest contribution comes from the calibration standard and that the instrument can measure the circles in a repeatable way under the measurement conditions. 

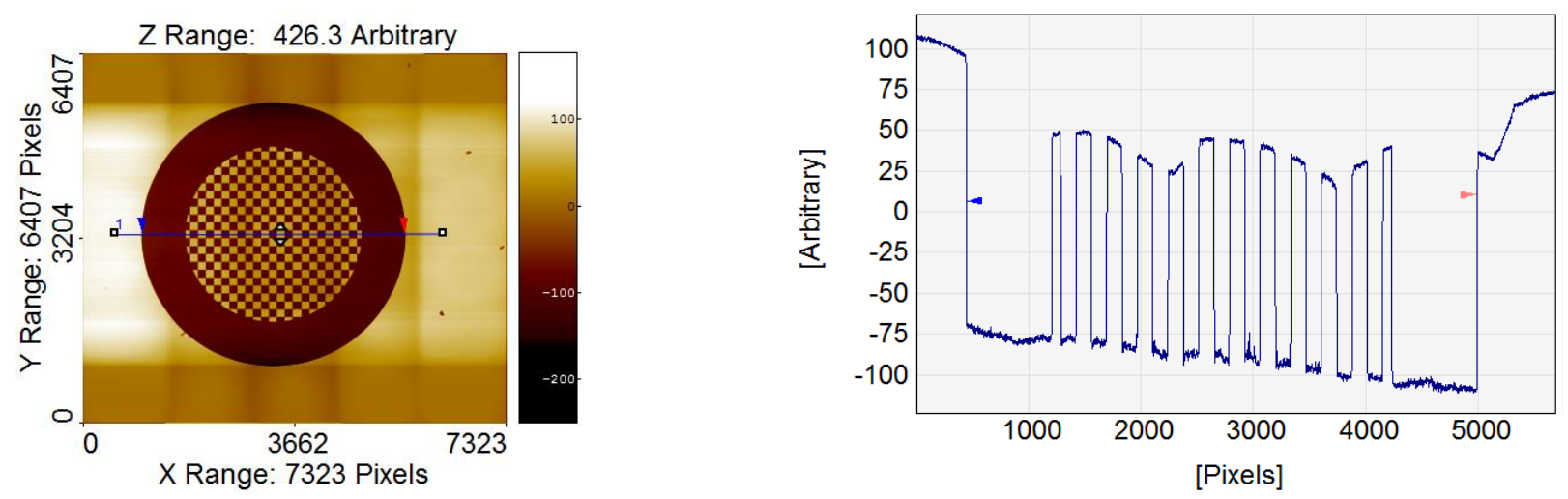

Figure 13: left) $2000 \mu \mathrm{m}$ circle reference with scaling diameter indicated by blue and red pointers, right) Measured diameter. Pixels are then converted into metric units by scaling

Table 3: $x-y$ calibration uncertainty value. All values are in $\mu m$.

\begin{tabular}{|c|c|c|c|c|}
\hline Nominal & $\mathrm{u}_{\mathrm{r}}$ & $\mathrm{u}_{\mathrm{p}}$ & $\mathrm{um}_{\mathrm{m}}$ & $\mathrm{U}$ \\
\hline 50 & 0.5 & 0.011 & 0.13 & 1.0 \\
\hline 250 & 0.5 & 0.011 & 0.13 & 1.0 \\
\hline 2000 & 1 & 0.212 & 0.13 & 2.1 \\
\hline
\end{tabular}

Z-axis calibration was performed on a step height carbide artefact with three nominal step heights: $2 \mu \mathrm{m}$, $5 \mu \mathrm{m}$ and $7 \mu \mathrm{m}$, developed by DTU [16], chosen because heights corresponded to a range of heights of plateaus as can be seen in Figure 14. A central area of interest of $1600 \mu \mathrm{m} * 1600 \mu \mathrm{m}$ of the calibration artefact was selected for ISO 5436-1 step-height measurement. Reference measurements were performed on a stylus profilometer (Form Talysurf Series 2 FTS by Taylor Hobson) according to [17]. Actual measurement of the step heights ABC, BGE, CGF was performed by extracting an average value from at approximately 948 samples per height on the focus variation image. The measured standard deviation in the calibration is $0.132 \mu \mathrm{m}, 0.045 \mu \mathrm{m}$ and $0.046 \mu \mathrm{m}$ for $3.570 \mu \mathrm{m}, 6.814 \mu \mathrm{m}$ and $10.118 \mu \mathrm{m}$ respectively (Table $4)$.

The measurement uncertainty on the height of relevant plateaus on the different samples is shown for the different materials in Table 5.

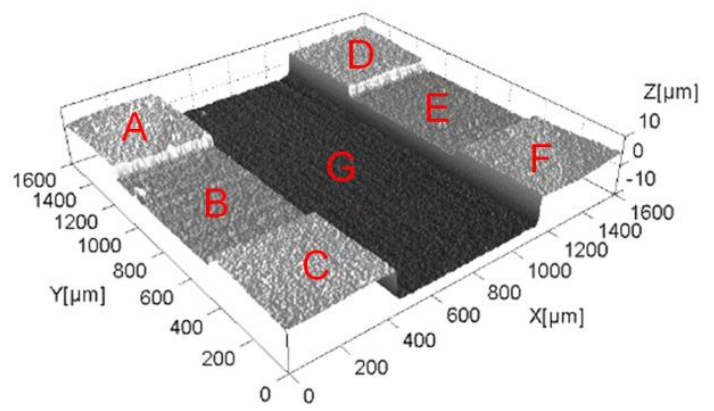

Figure 14: step height artefact measurement area

Table 4: Z-calibration tool certified measurement uncertainty. All values are in $\mu m$.

\begin{tabular}{|c|c|c|}
\hline Height name & Reference height & Expanded uncertainty, Ur $(\mathrm{k}=2)$ \\
\hline ABC & 3.570 & 0.132 \\
\hline BGE & 6.814 & 0.045 \\
\hline CGF & 10.118 & 0.046 \\
\hline
\end{tabular}


Table 5: uncertainty of plateau mean height $z_{\text {mean }}(z$ measurement). All values are in $\mu m$.

\begin{tabular}{|c|c|c|c|c|}
\hline Material & $\mathrm{u}_{\mathrm{r}}$ & $\mathrm{u}_{\mathrm{p}}$ & $\mathrm{um}_{\mathrm{m}}$ & $\mathrm{U}$ \\
\hline $\mathrm{a}$ & 0.02 & 0.015 & 0.01 & 0.05 \\
\hline $\mathrm{b}$ & 0.07 & 0.007 & 0.01 & 0.15 \\
\hline $\mathrm{c}$ & 0.02 & 0.07 & 0.01 & 0.05 \\
\hline
\end{tabular}

\section{Conclusions}

In this work, a novel method to characterise the stochastic surface topography of friction materials after a pin-on-plate low-speed wear test was introduced. The characterization method is based on height segmentation, identification and measurement of plateaus, which are features affecting brake performances such as wear, friction, noise and heat. Measurands are the number of plateau on the surface, equivalent diameter, length and breadth. The application of the method requires one working day to cover the complete specimen areas (alpha), (beta), (delta), (gamma). The implementation of the method in software would allow a much more efficient time use expanding measurement capacity. The method, based on ISO 25178-2, identifies the plateaus by determining their Upper Plateau Limit (UPL) and Lower Plateau Limit (LPL) through use of MPC, segmentation of the surface at LPL height threshold and filtering out debris according to an equivalent-diameter criterion. Once the plateaus are identified, the plateaus surface is characterised. The parameters used here to characterise the surfaces are: $\mathrm{S}_{\mathrm{pk}}, \mathrm{S}_{\mathrm{vk}}, \mathrm{S}_{\mathrm{mr} 1}, \mathrm{~S}_{\mathrm{mr} 2}$, and MPCs.

The method was successfully applied to focus variation height images for three materials: a woven fibre composite, a polyamide and a non-woven fibre composite, at two different levels of wear. This work covered material samples in the range 2-6 plateaus $\mathrm{mm}^{-2}, 3-9 \mu \mathrm{m}$ plateaus heights, $50-2600 \mu \mathrm{m}$ equivalent diameter and different plateau shapes. Traceability was provided by the use of reference artefacts for the $X-Y$ plane and Z-axis, ISO 5436. An expanded measurement uncertainty of $0.15 \mu \mathrm{m}$ for plateau heights up to $10 \mu \mathrm{m}$ and $3.5 \mu \mathrm{m}$ for plateau length and breadth dimensions in the range 50-2000 $\mu \mathrm{m}$ have been documented. The result of the characterization method also shows that plateaus identification parameters depend on the material. Furthermore, least worn specimens of all materials showed more plateaus at mid segmentation heights and larger plateau-covered areas than their most worn homologues. Least worn specimens of the woven fibre composite "a" and of the polyamide "b" had larger equivalent diameter and lower number of plateaus down at root level compared to their most worn homologues.

\section{Acknowledgements}

This work is an output of the Joint Research Project EMRP ENG 56 Drive Train Project supported by European Commission Framework Programme 7. Support is acknowledged with thanks to Svendborg Brakes A/S, Denmark, and to Konstantinos Poulios and Alessandro Stolfi, DTU Mechanical Engineering.

\section{ORCID IDs}

D Gonzales Madruga https://orcid.org/0000-0001-5359-0217

L De Chiffre https://orcid.org/0000-0002-6141-9580

\section{References}

1. Masotti D et al 2015 "Experimental Evaluation of Surface Morphology Characteristics During Stick-Slip Process at Low Speed Sliding Test", SAE Technical Paper 2015-01-2685 (https://doi:10.4271/2015-012685).

2. Alemani M, Gialanella S, Straffelini G, Ciudin R, Olofsson U, Perricone G and Metinoz I, 2017 Dry sliding of a low steel friction material against cast iron at different loads: Characterization of the friction layer and wear debris, Wear 376-7 1450-9;

3. ISO 25178-2: 2012, Geometrical product specifications (GPS) - Surface texture: aeral - part 2: terms, definitions and surface texture parameters (https://doi.org/10.3403/30154352).

4. MacAulay G D, Senin N, Giusca C L, Leach R K, 2014 Comparison of segmentation techniques to determine the geometric parameters of structured surfaces, Surface Topography: Metrology and Properties 2 044004;

5. Abdel-Aal H A, 2016 Functional surfaces for tribological applications: inspiration and design, 2016 Surf. Topogr.: Metrol. Prop. 4 043001; 
6. Ricciardi V, Augsburg K, Gramstat S, Schreiber V and Ivanov V, 2017 Survey on modelling and techniques for friction estimation in automotive brakes, Applied Sciences, 2017, 7, 873;

7. Poulios K, Drago N, Klit P and De Chiffre L, 2014 A reciprocating pin-on-plate test-rig for studying friction materials for holding brakes. In: Wear, Vol. 311 40-7

8. Ostermeyer G P and Mueller M 2006, Dynamic Interaction of friction and surface topography in brake systems, Tribology International 39 370-380

9. Hammerström L, 2006 Mechanisms and phenomena in braking and gripping, Uppsala Universitet, PhD thesis, 2006

10. ISO 13565-3: 2000, Geometrical Product Specifications (GPS) - surface texture: profile method: surfaces having stratified functional properties - part 3: height characterization using the material probability curve (https://doi.org/10.3403/02108322)

11. Drago N, De Chiffre L and Poulios K, 2014 Uncertainty of pin height measurement for the determination of wear in pin-on-plate test, CIRP Journal of Manufacturing Science and Technology 7 106-11.

12. De Chiffre L, Hansen H N, Andreasen J L, Savio E and Carmignato S 2011 Geometrical Metrology and Machine Testing, DTU Mekanik, book, pages 229-311, 2015

13. MacAulay G D, Giusca $C L 2016$ Assessment of uncertainty in structured surfaces using metrological characteristics, CIRP Ann. 65 533-6

14. JCGM 100:2008 BIPM, Evaluation of measurement data - Guide to the expression of uncertainty in measurement (Sèvres: Bureau International des Poids et Mesures)

15. Hu S, Huang W, Brunetiere N, Liu X and Wang Y 2017 Truncated separation method for characterizing and reconstructing bi-Gaussian stratified surfaces, Springer, Friction 5 32-44

16. Tosello G, Haitjema H, Leach R K, Quagliotti D, Gasparin S and Hansen H N 2016 An international comparison of surface texture parameters quantification on polymer artefacts using optical instruments CIRP Ann. 65 529-32;

17. De Chiffre L, Carli L and Eriksen R S 2011 Multiple height calibration artefact for 3D microscopy, CIRP Ann. 60 535-8. 